\title{
Será que eu consigo levar essa gestação até o fim? A experiência materna da gestação no contexto da reprodução assistida'
}

\author{
Will I manage to go through this pregnancy to full term? \\ The maternal experience during pregnancy in the \\ context of assisted reproduction
}

\author{
Lia Mara Netto DORNELLES² \\ Rita de Cássia Sobreira LOPES 3
}

\begin{abstract}
Resumo
Quando o projeto parental não pode ser realizado em decorrência de infertilidade no casal, é possível recorrer às técnicas de reprodução assistida para a realização desse projeto. Entretanto, o desgaste físico e emocional decorrente desses procedimentos pode conferir à gestação e à parentalidade um caráter específico, com repercussões ainda pouco conhecidas. Por meio deste estudo qualitativo, com três mulheres que engravidaram por diferentes técnicas de reprodução assistida, buscou-se conhecer o processo de tornar-se mãe nesse contexto, com entrevistas no terceiro trimestre de gestação. A discussão dos resultados deu-se a partir da Constelação da Maternidade, da compreensão da vivência materna na gestação e da noção de estágios da concepção em casais inférteis. Os resultados apontaram que a experiência da gestação caracterizou-se pelo predomínio do medo de perder o bebê e sentimentos de incapacidade de levar a gestação a termo, conferindo singularidade a esse momento.
\end{abstract}

Unitermos: Gestação. Infertilidade. Tecnologia reprodutiva.

\begin{abstract}
When plans to become parents cannot be realized due to a couple's infertility, it is possible to resort to assisted reproduction techniques. However, the physical and emotional stress caused by these techniques may accord pregnancy and parenthood specific characteristics, with yet unknown repercussions. Through this qualitative study, based on interviews with three women in the third trimester of pregnancy, who conceived with the aid of different assisted reproduction techniques, this study aimed to understand the process of becoming a mother in this context. The results were discussed based on the concept of maternal constellation, the understanding of the experience of pregnancy and the notion of stages of conception in infertile couples. The results primarily revealed a fear of losing the baby and feelings of being incapable of having a normal pregnancy, bringing unique challenges to this moment.
\end{abstract}

Uniterms: Pregnancy. Infertility. Reproductive technology.

\section{$\boldsymbol{\nabla \nabla \nabla \nabla}$}

1 Artigo elaborado a partir de tese de L.M.N. DORNELLES, intitulada "Tornar-se pai e mãe no contexto da reprodução assistida". Universidade Federal do Rio Grande do Sul, 2009. Apoio: Conselho Nacional de Desenvolvimento Científico e Tecnológico.

2 Universidade de Caxias do Sul, Centro de Ciências Humanas. R. Francisco Getúlio Vargas, 1130, Petrópolis, 95020-972, Caxias do Sul, RS, Brasil. Correspondência para/Correspondence to: L.M.N. DORNELLES.E-mail: <liamaradornelles@gmail.com>.

3 Universidade Federal do Rio Grande do Sul, Instituto de Psicologia. Porto Alegre, RS, Brasil. 
Quando o projeto parental não pode ser realizado em decorrência de infertilidade no casal, é possível recorrer às Técnicas de Reprodução Assistida (TRA), como uma tentativa de concretização desse projeto. Essas técnicas referem-se a todos os tratamentos ou procedimentos que envolvem a manipulação de óvulos e espermatozoides humanos, com a finalidade de estabelecer uma gravidez, sendo indicadas quando as intervenções clínicas e/ou cirúrgicas não são capazes de promover a gestação por si.

Dentre tais técnicas, encontram-se: (1) Fertilização in Vitro (FIV), que envolve a remoção de óvulos dos ovários e a fertilização dos mesmos em laboratório; (2) Inseminação Intrauterina (IU), que consiste na introdução de espermatozoides no interior do útero; (3) Injeção Intracitoplasmática de Espermatozóides (ICSI), que objetiva a formação do embrião por meio do encontro entre os gametas masculino e feminino; (4) Doação de Gametas (GIFT), na qual oócitos da mulher doadora são fertilizados com o sêmen do marido ou companheiro da paciente (receptora) e os embriões são transferidos para o útero da receptora, e (5) gestação de substituição (barriga de aluguel), nos casos em que há um útero de outra mulher, que recebe os embriões e genes, situação essa menos frequente no contexto brasileiro (Ferriani \& Navarro, 2004). Sendo assim, essas técnicas tornaram possível a diversos casais a obtenção da gravidez e a realização do projeto parental, embora possuam limitações quanto a seus resultados, principalmente nos casos em que a idade da mulher é superior a 35 anos (Balmaceda et al., 2001).

Portanto, em decorrência da luta para conceber e do comprometimento físico e emocional exigido, tornar-se mãe no contexto da reprodução assistida apresenta características especiais, que podem surgir como desafios únicos para a mulher. Assim como a gestação representa a realização de um sonho, pode também ser um evento problemático (Repokari et al., 2005), no qual novas vivências e desafios se impõem ao casal, e cujas implicações ainda são pouco conhecidas (McMahon, Gibson, Leslie, Cohen \& Tennant, 2003).

Nesse contexto desafiador, é possível pensar que a mulher, já durante a gestação, vivencia antecipadamente alguns aspectos presentes na "constelação da maternidade", proposta por Stern (1997). Segundo o autor, o nascimento de um bebê implica o surgimento de uma nova, única e temporária organização psíquica na mãe, a qual será o eixo organizador de sua vida durante meses ou anos, e contempla os seguintes temas: (1) vida-crescimento; (2) relacionar-se primário; (3) matriz de apoio e (4) reorganização da identidade. O tema vida-crescimento refere-se à capacidade da mãe de manter o bebê vivo e de propiciar seu crescimento e desenvolvimento físico. Engloba diversos medos, tais como de que o bebê morra, que pare de respirar, que não coma, que definhe, que se desidrate, que caia, ou seja, que ocorra um assassinato por profunda inadequação, ou, então, que viva, mas não se desenvolva bem, e isso requeira hospitalizações ou sua substituição por uma mãe melhor. O segundo tema, relacionar-se primário, refere-se ao envolvimento social e emocional da mãe com seu bebê. Surgem, nessa fase, dúvidas sobre sua capacidade de amá-lo, sentir que é amada por ele, reconhecer que ele é realmente seu bebê. O tema seguinte, matriz de apoio, diz respeito à necessidade da mãe de criar, permitir, aceitar e regular uma rede de apoio protetora e boa, que a ajude a realizar as duas tarefas anteriores. O quarto e último tema, reorganização da identidade, relaciona-se à necessidade da mãe de transformar e reorganizar a sua identidade, de redirecionar seus investimentos emocionais, sua distribuição de tempo e energia, bem como suas atividades.

Em um levantamento de publicações sobre a parentalidade no contexto da reprodução assistida, foram encontrados estudos que contemplaram o períodogestacional (Colpin, DeMunter \&Vandemeulebroecke, 1998; Fisher, Hammarberg \& Baker, 2008; Hjelmstedt, Widström, Wramsby \& Collins, 2003a; Hjelmstedt, Widström, Wramsby, Mattiesen \& Collins, 2003b; Klock \& Greenfeld, 2000; Stanton \& Golombok, 1993; Ulrich, Gagel, Hemmerling, Pastor \& Kentenich, 2004), sendo bastante diversificado o foco das investigações sobre essa temática. Enquanto alguns estudos investigaram ansiedade (Klock \& Greenfeld, 2000; Stanton \& Golombok, 1993), depressão (Klock \& Greenfeld, 2000), saúde mental (Fisher et al., 2008), ajustamento conjugal, outros abordaram autoestima (Klock \& Greenfeld, 2000), recompensas e preocupações trazidas pela maternidade (Klock \& Greenfeld, 2000), resposta emocional à gestação (Hjelmstedt et al., 2003a; 2003b), peculiaridades da gestação (Ulrich et al., 2004), atitudes em relação à gestação (Stanton \& Golombok, 1993), expectativas e atitudes em relação ao bebê e à parentalidade, traços de perso- 
nalidade, reações à infertilidade (Hjelmstedt et al., 2003a; 2003b) e apego pré-natal (Colpin et al., 1998; Stanton \& Golombok, 1993).

O exame global dos estudos empíricos sobre a parentalidade no contexto das TRA permite tecer algumas considerações. Em relação aos principais resultados obtidos, destaca-se que o medo de perder o bebê encontra-se elevado no grupo de participantes que concebeu por FIV, comparado ao grupo que concebeu espontaneamente (Hjelmstedt et al., 2003a; 2003b), talvez pelo investimento físico, financeiro e emocional necessário para a concretização da gestação. Outro aspecto frequentemente investigado foi a ansiedade. Os resultados dos estudos que compararam o grupo FIV com o grupo que concebeu naturalmente se mostraram inconsistentes. Enquanto alguns estudos apontaram redução da ansiedade no grupo FIV ao longo da gestação (Klock \& Greenfeld, 2000; Stanton \& Golombok,1993), em outros, os níveis de ansiedade mantiveram-se iguais tanto no grupo FIV, quanto no que concebeu naturalmente (Stanton \& Golombok,1993).

Os estudos que investigaram a resposta emocional à gestação encontraram diferenças entre os dois grupos (Hjelmstedt et al., 2003b), sendo que no grupo FIV observou-se idealização, assim como apareceram idealizadas as expectativas da futura mãe em relação à parentalidade (Fisher et al., 2008; Hjelmstedt et al., 2003a). Já o apego materno-fetal, um construto importante da parentalidade, surgiu atrelado à qualidade da relação conjugal (Colpin et al., 1998), não diferindo entre os grupos (Stanton \& Golombok, 1993).

Quanto aos aspectos metodológicos, observou-se a predominância de estudos quantitativos, com o emprego de instrumentos padronizados (escalas e questionários) e comparação entre grupos (FIV x concepção natural). Percebeu-se, entre esses estudos, uma preocupação em apontar sintomas e dificuldades apresentadas pelas participantes nesse contexto, valendo-se de comparações de resultados obtidos por meio de escalas e inventários, sem, no entanto, buscar a compreensão da vivência desses momentos (gestação e transição para a parentalidade).

Em geral, pelo caráter quantitativo, foram utilizadas grandes amostras, avaliadas por meio de instrumentos fechados e padronizados, que detectaram aspectos isolados, mas não acessaram o tornar-se mãe nesse contexto. Os dados originados a partir desses instrumentos, embora relevantes para identificar questões de pesquisa e intervenção, constituem apenas fragmentos do complexo processo de transição para a parentalidade e possibilitam uma compreensão parcial e fragmentada sobre o mesmo.

Concluindo, considera-se que o complexo processo de tornar-se mãe, nesse contexto, estende-se para além do que é mensurável. Presença versus ausência, maior intensidade versus menor intensidade são dicotomias incapazes de abarcar a totalidade da experiência psíquica vivida por essas mulheres ao longo desse processo. Essa experiência se inicia com dor psíquica e coloca o sujeito frente a frente com sua história de vida. Além disso, envolve transformações psíquicas profundas, passando pela aceitação de uma nova identidade de mulher fértil e estendendo-se até o exercício da parentalidade, caminho percorrido com muitos conflitos, desafios e impasses. Considera-se, portanto, que esse processo de desenvolvimento, que se dá na vida adulta, não tem sido bem contemplado pelos estudos da área.

\section{Método}

\section{Participantes}

Participaram deste estudo três gestantes oriundas de um projeto maior, intitulado Transição para a parentalidade e relacionamento conjugal no contexto da reprodução assistida: da gestação ao primeiro ano do bebê, desenvolvido pelo Núcleo de Infância e Família (Nudif) da Universidade Federal do Rio Grande do Sul, em parceria com o Hospital de Clínicas de Porto Alegre. (HCPA).

A escolha desse número de participantes se adequou ao critério de saturação para estudos qualitativos com instrumentos abrangentes (Barker, Pistrang \& Elliot, 1994). As três participantes do estudo, Vitória, Simone e Raquel, cujos nomes são fictícios para preservar-Ihes a identidade, conceberam a partir do uso de diferentes TRA e se encontravam no terceiro trimestre da gestação do primeiro filho. Todas residiam na região metropolitana de Porto Alegre. Vitória iniciou a investigação de sua infertilidade 5 anos antes de submeter-se à inseminação artificial, sendo de dez anos o tempo de relacionamento do casal. Após uma extensa investi- 
gação, foi constatado que a causa da infertilidade do casal era masculina, ocorrendo a concepção em sua primeira tentativa. Já Simone e seu esposo começaram a pensar na hipótese de ter filhos após 7 anos de relacionamento: foi constatado que a causa da infertilidade era feminina. Entre a primeira tentativa fracassada e a doação de gametas passaram-se 2 anos. Raquel, no entanto, submeteu-se à sua primeira fertilização in vitro 3 anos após iniciar a investigação da infertilidade, cuja causa não foi identificada. O tempo decorrido entre a primeira e a segunda fertilização, na qual o casal obteve sucesso, não foi identificado por Raquel de forma clara. A Tabela 1, apresenta as características sociodemográficas das participantes.

A inclusão de participantes que utilizaram diferentes técnicas de reprodução assistida em um mesmo grupo justifica-se pelo critério de heterogeneidade da amostra. Segundo Patton (2002), a utilização desse critério tem por objetivo capturar e descrever os principais temas que permeiam a diversidade, sendo que também os padrões comuns, que emergem da heterogeneidade, são relevantes e valiosos para capturar as experiências básicas e dimensões de determinado fenômeno. Dessa forma, são contempladas as especificidades de cada experiência, bem como as similaridades entre os casos, presentes na heterogeneidade.

O estudo foi aprovado pelo Comitê de Ética em Pesquisa do Hospital das Clínicas de Porto Alegre, sob $n^{\circ} 07 / 153$, em 6 de julho de 2007, tendo todas as participantes assinado um Termo de Consentimento Livre e Esclarecido antes de sua inclusão na amostra.

\section{Instrumentos}

Foram utilizados os seguintes instrumentos: (1) Entrevista de Dados Demográficos do Casal (Nudif, 1998a):

Tabela 1. Características sociodemográficas das participantes. Porto Alegre (RS), 2009.

\begin{tabular}{lclcc}
\hline Participantes $^{*}$ & Idade & Escolaridade & Tentativas & TRA $^{* *}$ \\
\hline Vitória & 37 & Superior & 1 & IA \\
Simone & 44 & Superior & 2 & DG \\
Raquel & 25 & Médio & 2 & FIV \\
\hline
\end{tabular}

*O nome das participantes é fictício; ${ }^{* *}$ Técnicas de Reprodução Assistida: IA: inseminação artificial; DG: doação de gametas; FIV: fertilização in 492 vitro. esse instrumento visa à obtenção de informações sociodemográficas a respeito dos participantes. É composto por questões que enfocam estado civil, pessoas que vivem na mesma residência, ocupação, escolaridade, religião e etnia, além de informações para contato, sendo que, para fins deste estudo, foram utilizados apenas os dados das gestantes; e (2) Entrevista sobre a Gestação e as Expectativas da Gestante (Nudif, 1998b), que investiga (1) como a gestante vem vivenciando esse período, desde que soube a notícia da gravidez; (2) suas expectativas em relação ao futuro; (3) percepção de como o marido vivencia a gestação; (4) reação das famílias face à gestação; (5) expectativas em relação ao bebê; (6) percepção do impacto das TRA sobre a vivência da gestação.

\section{Procedimentos}

A partir de um levantamento realizado pela equipe do Serviço de Ginecologia e Obstetrícia do HCPA, com o intuito de verificar quais de suas pacientes haviam obtido sucesso no tratamento, foi encaminhada à pesquisadora uma listagem contendo nomes e telefones das mesmas para posterior contato. As gestantes foram contatadas por telefone para a explicação dos objetivos e da forma de realização do estudo. Com aquelas que demonstraram interesse, foi marcado um encontro, no qual foi apresentado o Termo de Consentimento Livre e Esclarecido. Em caso de concordância, foi iniciada, na mesma oportunidade, a realização da coleta de dados, por meio de entrevistas estruturadas.

\section{Resultados e Discussão}

Por meio dos três casos estudados, buscou-se investigar o processo de tornar-se mãe, em mulheres que engravidaram por meio de TRA, levando-se em consideração o conteúdo das entrevistas realizadas no terceiro trimestre gestacional. Os dados obtidos a partir das entrevistas foram submetidos a uma análise qualitativa de conteúdo (Laville \& Dione, 1999), com categorias a priori.

Os resultados foram discutidos a partir da literatura, tendo como principais eixos interpretativos a "constelação da maternidade", proposta por Stern (1997), 
uma vez que se identificaram, no relato das participantes, também alguns temas característicos do período após nascimento do bebê. Além disso, para melhor compreensão da vivência materna na gestação, recorreu-se a Raphael-Leff (1997), pois essa autora se dedicou ao estudo do período gestacional, enquanto Stern (1997) ateve-se aos temas presentes após o nascimento do bebê. Por fim, os dados foram analisados à luz da noção de estágios da concepção em casais inférteis, proposta por Sandelowski, Harris e Holditch-Davis (1990), a qual considera que a concepção para os casais inférteis é um processo longo, no qual passam do estágio de "obter uma gravidez", isto é, do período de tratamento, ao de "estar grávido", referindo-se à dificuldade encontrada pelos casais em admitir que obtiveram sucesso no tratamento. Dessa forma, apontam que esse processo engloba três aspectos: "forçar" a concepção, por meio de tratamento; resolver a dicotomia da concepção, referindo-se ao fato de estar ou não grávida; e conciliar a percepção da concepção como uma ideia e um evento, podendo então acreditar que a gravidez existe.

A escolha desses autores constitui uma tentativa de contribuir para o entendimento da vivência da gestação no contexto específico da reprodução assistida.

\section{Tema vida-crescimento}

O tema vida-crescimento, já presente na gestação, foi expresso por meio da incerteza e do medo de não ser capaz de gerar um bebê saudável e garantir sua sobrevivência, ainda intraútero, vindo a mobilizar na gestante sentimentos e fantasias que interferiram na maneira como foi vivida a gestação: "...daí comecei a me estressar... tinha que ficar em repouso, deitada o tempo todo, né? Com medo de perder... aquela coisa toda, né?...Foi o susto dos riscos, assim: será que eu consigo levar essa gestação até o fim?" (Simone). Além disso, o medo de não ser capaz de gerar "coisas boas" também esteve presente durante esse período: medo de "ter uma criança deformada" e o bebê nascer "com alguma coisa, que a gente vai ter que administrar" (Vitória), sendo necessário "parar de trabalhar nos primeiros meses" (Raquel).

Embora esses aspectos também possam ser encontrados nas gestantes que conceberam de forma natural, ressalta-se que as participantes deste estudo encontravam-se no último trimestre de gestação, quando a preocupação mais frequente é com o parto. A presença marcante do tema, no relato dessas gestantes, conferiu a esse período um colorido especial. Observou-se nas mães entrevistadas que esses medos tornaram-se eixo central em sua vida, em torno do qual outras áreas de interesse gravitaram. Houve monitoramento de sinais que pudessem indicar que o bebê estava vivo e desenvolvendo-se bem, ocorrendo uma constante avaliação da capacidade da mãe de possuir aspectos bons dentro de si.

Raphael-Leff (1997) destacou que as gestações posteriores à infertilidade, com frequência, são preciosas e se tornam supervalorizadas e acompanhadas de temores de que, mesmo ligeiros lapsos de concentração, possam causar perda do bebê. Apesar da sensação de vulnerabilidade presente no primeiro trimestre de gestação, o reconhecimento das alterações sutis no corpo reforçam a crença, na gestante, de que ela é capaz de gerar o bebê e dar à luz. No entanto, neste estudo verificou-se que o sentimento de vulnerabilidade das mães se estendeu ao longo de toda a gestação, sendo que as alterações inerentes a esse período foram percebidas como uma possível ameaça de perda do bebê. Houve angústia e descrença na possibilidade de realizar o desejo de tornar-se mãe; o medo de deparar-se com a frustração de perder o bebê permeou os discursos, evidenciando a dificuldade em acreditar que a gestação foi bem-sucedida e que o bebê estava se desenvolvendo bem. Esse medo pode ser ilustrado pelo relato de uma participante: "...se ele não mexe [quando acorda pela manhã] eu já fico preocupada, já começo a conversar, a estimular ele" (Raquel). No que concerne à gestação espontânea, estudos realizados por Piccinini, Gomes, Moreira e Lopes (2004) e por Piccinini, Gomes, Nardi e Lopes (2008), no mesmo período gestacional, utilizando os mesmos instrumentos deste estudo, não evidenciaram o medo da perda do bebê no último trimestre de gestação, mas o receio de malformação ou prematuridade. Além disso, a preocupação central dessas muIheres foi quanto a sua competência nos cuidados com o bebê após o nascimento, a seu futuro e a sua educação.

\section{Tema relacionar-se primário}

A necessidade de conexão e sintonia com o bebê pode ser observada pela maneira intensa como Raquel 
e Vitória expressaram seus desejos de dedicação exclusiva ao bebê, tais como: "... parar tudo e só viver a maternidade"; "... sentir-se realizada como mãe" (Vitória) e "... imaginar-se vivendo só para o filho" (Raquel).

Outro aspecto a ressaltar sobre o envolvimento da mãe com o bebê foi o fato de Vitória "sentir-se consumida emocionalmente" pelos preparativos que antecederam o nascimento da filha, sendo que o período de "nove meses é curto" para dar conta de tantas incertezas e angústias despertadas durante a gestação. O medo de que a gestação não fosse a termo, principalmente nos primeiros trimestres, foi intenso nessa mãe, tornando-se um obstáculo para que vivesse a gestação de forma plena.

\section{Tema matriz de apoio}

Em seus relatos, as gestantes apontaram que se fortaleceu o relacionamento do casal e houve aumento da coesão entre ambos, quando viveram juntos a experiência da infertilidade, exemplificado ao referirem "... ter recebido muito apoio" (Simone), "recebi apoio do meu marido, em primeiro lugar ele que tá, que tá sempre junto" (Raquel); "Essa gentileza, esse cuidado, essa apoio assim [recebido do marido] (Vitória). Cabe ressaltar que as gestantes desejavam compartilhar com os maridos os cuidados com o bebê, embora acreditassem que o envolvimento maior, no dia a dia, seria delas, uma vez que os mesmos, antes de tudo, eram vistos como provedores, aqueles que deveriam garantir o sustento da família.

As participantes sentiram-se apoiadas também pelos familiares mais próximos: "A minha mãe, quando eu precisei ficar em repouso ela..., ela vem do interior e fica comigo, meacompanha, né?" (Simone); "... principalmente a minha mãe, a minha mãe ela tá, tá me dando bastante força..."; "tem a sobrinha do meu marido" (Raquel); "Essas primas... são primas mais novas, desde o início elas estão assim... [dando apoio]" (Vitória).

\section{Tema reorganização da identidade}

Já na gestação, foi possível visualizar a reorganização da identidade da gestante, que requer um novo trabalho mental. Na especificidade da reprodução assistida, essas gestantes necessitaram lidar também com as cicatrizes deixadas pelo diagnóstico da infertilidade, havendo a transição de uma identidade de mulher infértil para a de mulher fértil, "grávida" de esperanças por tornar-se mãe.

A confirmação da gravidez gemelar de Simone desencadeou momentos desorganizadores e repletos de sentimentos ambivalentes e a necessidade de absorver a ideia de que seriam gêmeos e haveria riscos implícitos. Além disso, a descrença na capacidade de garantir a sobrevivência dos bebês, preocupação dominante durante a gestação nesse contexto, pode ter sido um obstáculo que dificultou a transformação e a reorganização de sua identidade.

Já no relato de Vitória, chamou a atenção o fato de demonstrar, de maneira consciente, o medo de perder sua identidade, como consequência das mudanças profundas provocadas pela maternidade: "... pode ser que venha para uma coisa positiva [mudanças trazidas pela maternidade], pode ser que não, ... perdi a minha personalidade, minha identidade... . Quem sou eu?".

Portanto, verificou-se no presente estudo que a gravidez foi marcada pelo medo de perder o bebê e pela descrença de poder garantir sua sobrevivência, ainda intraútero, com implicações na vivência das diferentes etapas da gestação e as temáticas da constelação da maternidade inerentes a cada uma delas. Acredita-se que as marcas deixadas pela infertilidade, aplacadas pelo sucesso do tratamento, foram intensamente reavivadas no período gestacional, com implicações na maneira como esses casais vivenciaram a gestação. Ribeiro (2004) acrescenta que a experiência da infertilidade pode intensificar as fantasias de que há coisas estragadas no interior do corpo da mulher, tornando-se difícil imaginar ou fantasiar que um bebê possa desenvolver-se em um interior danificado - interior do corpo e do psiquismo. Esse processo, segundo Ribeiro (2004), corre o risco de não ser apenas momentâneo, vindo a "aprisionar" o sujeito nessa situação de sofrimento psíquico, "contaminando" outros de seus campos de realização.

Além da constelação da maternidade, dois outros aspectos presentes nesse período merecem destaque e serão discutidos a seguir: a presença de estágios da concepção e o bebê imaginário. 


\section{Estágios da concepção}

Do ponto de vista físico, cabe salientar que, uma vez constatada a gravidez com auxílio das TRA, espera-se que ela transcorra da mesma forma que uma gravidez espontânea, embora possam ser frequentes casos em que há prematuridade dos bebês e gestação gemelar, que conferem à gestação um caráter especial ao torná-la de risco.

Nesse sentido, cabe lembrar o estudo de Sandelowski et al. (1990), o qual traz a ideia de que, para os casais inférteis a concepção pode ser dividida em estágios, passando do estágio de "obter uma gravidez" ao de "estar grávido".

Ao longo desses estágios podem ser detectados três aspectos: (1) "forçar" a concepção (por meio dos procedimentos); (2) resolver a dicotomia da concepção (estar ou não estar grávida); e (3) conciliar a percepção da concepção como uma ideia e um evento (acreditar que a gravidez existe). Neste estudo, em particular, destacam-se os dois ultimos aspectos.

Quanto ao aspecto "estar ou não estar grávida", cabe destacar que este relaciona-se ao período gestacional e refere-se ao fato de que, apesar de ter os óvulos fertilizados, a mulher receia admitir o status de grávida. Neste estudo, esse receio pôde ser verificado pelas falas: "Primeiro eu fiz o teste de sangue... só acreditei mesmo na hora daecografia, queeu fizcom cinco semanas". (Raquel); "Eu estava com uma expectativa esegurando um pouco a minha ansiedade. Daí, tá... vencer aquele período de um certo repouso, cuidado, né? Porque a gente sabia que tinha que grudar, né? [nidação]; "Mas essa barriga é minha, é barriga de gorda... não é barriga de grávida" (Vitória).

Já o aspecto seguinte, referente à crença de que a gravidez existe, aponta para a dificuldade evidenciada pelas gestantes deste estudo em acreditar que a gestação está transcorrendo e que há um bebê se desenvolvendo em seu útero: "... eu não tava acreditando, só na hora daeco mesmo queeu acreditei, né...queeuvi" (Raquel); "Eu me sinto assim... esperançosa que vai dar tudo certo, né?" (Simone).

\section{Bebê imaginário}

Outro aspecto importante a ser destacado refere-se ao bebê imaginário da mãe, fruto do desejo de gravidez, da interação mãe/feto, que faz parte de seus devaneios e é composto por impressões e desejos oriundos de experiências anteriores (Lebovici, 1992). $O$ ventre materno torna-se um abrigo de esperanças, vontades, desejos e ansiedades (Raphael-Leff, 1997); constitui-se no receptáculo dos sonhos e das expectativas maternas (Lebovici, 1987). Mesmo antes de nascer, são atribuídas características ao bebê, que correspondem a representações do mundo interno da mãe e que servem como pano de fundo para a construção das características do bebê imaginário (Raphael-Leff, 1997), contribuindo também para a percepção da futura criança como um indivíduo (Brazelton \& Cramer, 1992).

Algumas características físicas e psicológicas atribuídas aos bebês deste estudo merecem atenção. Segundo Vitória, a filha vai nascer com "os cabelinhos arrepiados, que nem o pai"; "vai ser bem-sapeca, porque ela nada bastante na barriga da mãe dela...". Já Simone, embora estivesse no terceiro trimestre de gestação gemelar, percebeu os bebês durante as ecografias como "fetos" e de maneira fragmentada (fêmur, cabeça, nariz, etc.):...assim, eles tão... feto, naverdade"; "E daíaquela noção de mão, braço, perna, pezinho, mãozinha". Provavelmente, esses bebês permaneciam ainda fetos no psiquismo dessa gestante, passíveis de serem "abortados" e, portanto, com poucas características de bebês.

O relato das participantes deste estudo sugeriu que, à medida que os bebês se desenvolviam em seu útero e as ecografias apresentavam imagens mais nítidas, surgiu também um correspondente psíquico nessas gestantes, como se aqueles minúsculos pontos que iam se sobrepondo na tela, eformando a cada nova ecografia uma imagem mais nítida, também as auxiliassem a incrementar sua frágil crença de que o bebê estava se desenvolvendo bem: "Que agora eu tô mais tranquila. Ah, os bebêsjá tão formadinhos, já fiz translucência nucal..." (Simone). Mesmo assim, embora a realidade externa, por meio dos exames clínicos e de imagens, apontasse que a gravidez estava transcorrendo bem, a dúvida em relação à capacidade de produzir"coisas boas"e o medo de gerar um bebê com malformações persistiram nas gestantes deste estudo: "O peso e o desenvolvimento tábom... mas a gente sempre se preocupa se é que não vai surgir alguma coisa, né? Porque às vezes escapa ao exame" (Simone). 
É interessante observar, também, a maneira peculiar como os bebês foram referidos nesse período. Uma imagem já projetada no futuro foi atribuída a um dos bebês, conferindo-Ihe uma posição de destaque, de "supermodelo", uma "superprodução" que viria a gratificar o narcisismo materno. Vitória teria uma filha muito especial, "uma Gisele Bündchen, igual à mãe dela...", logo, também seria especial. Por outro lado, Raquel comentou que "aquilo ali [bebê], foi conseguido", revelando que o filho era percebido como algo que veio de fora, foi adquirido e que "já é irritadinho como a mãe". Por outro lado, Simone apontou que "só consegue imaginar aquilo que o médico disse", referindo-se aos dados concretos sobre os bebês, tais como número de bebês, sexo, peso aproximado e características físicas da doadora, que eram semelhantes às suas.

Szejer eStewart (1997) referiram que são também atribuídas aos bebês, ainda durante a gestação, características decorrentes do signo correspondente ao período em que deverão nascer. Portanto, a linguagem astrológica tem a função de atribuir à criança uma primeira identidade que a marcará. Essa personificação facilita a inserção do bebê na teia familiar, incorporando-o na história de seus genitores. Nesse sentido, destacam-se nuances da identidade atribuída ao bebê pela mãe, decorrente do signo ao qual ele pertenceria. Segundo Vitória, ao nascer sob o signo de Aquário, também sua filha herdaria suas características e seria "espoletinha", enquanto Raquel atribuiu ao filho as características do signo de Escorpião, o mesmo de seu esposo, vindo o bebê a ser "bem ativo, brabo e ansioso". Dessa forma, os bebês foram incluídos na linhagem parental, com características que apontaram sua condição de pertencer a essa família.

Segundo Maldonado (2002), aos movimentos do bebê são atribuídos significados e algumas características pessoais, de acordo com a interpretação da mãe, como uma forma de personificá-lo e inseri-lo em seu psiquismo. O bebê pode ser percebido como carinhoso ou delicado, se os movimentos são tidos como suaves; ou pode ser percebido como agressivo, se os movimentos são interpretados como socos ou "patadas". Vitória percebeu que a filha "nada bastante" em seu ventre, enquanto para Raquel os movimentos do feto foram interpretados como uma maneira de the comunicar que não estava confortável, pois ele "émuito a tivo... chuta atéque ela vire de lado práele poder... conseguirdescansar."
Aulagnier (1990) destacou a relevância da inserção do bebê imaginário no psiquismo da mãe, como forma de existência desse bebê em separado, enquanto Brazelton e Cramer (1992) afirmaram que essa personificação permite à mãe a percepção de que o bebê que está em seu ventre não lhe é completamente estranho. As características atribuídas pelas mães entrevistadas ao seu bebê evidenciaram a maneira como personificaram esses bebês, atribuindo-lhes aspectos especiais e características familiares, sendo que, dessa maneira, os bebês imaginários também foram gestados no psiquismo dessas mães.

\section{Considerações Finais}

O panorama da reprodução humana frente ao diagnóstico de infertilidade mudou drasticamente a partir do século XX. Se o projeto parental é inviabilizado, casais inférteis podem recorrer às técnicas de reprodução assistida, em busca da realização do desejo de maternidade e paternidade, questionando os limites impostos pela biologia. Desde o século passado, o homem tem sido testemunha dos avanços tecnológicos no campo da reprodução assistida, que trouxe uma mudança radical para a existência humana. A partir do nascimento de Louise Brown, o primeiro bebê de proveta, em 1978, na Inglaterra, mais de um milhão de crianças nasceram em decorrência das TRA. Três décadas após seu nascimento, Louise Brown ainda atrai a atenção sobre si, não somente como o primeiro bebê de proveta, mas como a primeira mulher concebida por reprodução assistida, que gestou um bebê de forma natural, reforçando a atualidade e relevância do tema.

No contexto da reprodução assistida, a procriação está dissociada da atividade sexual. Na verdade, prescinde desta. Sendo assim, a busca pelo projeto parental tem seu início de forma diferenciada, com a inclusão de um terceiro na relação, o médico, além do estigma da infertilidade, que deixa marcas na trajetória desses indivíduos rumo à parentalidade.

A história pessoal de cada mulher, as experiências vividas e o desejo de ter filhos ganham um colorido especial no contexto da reprodução assistida: atualiza antigas feridas, traz novos sentimentos e medos, que formarão a tessitura da gestação psíquica do bebê que 
está a caminho. Acreditar na possibilidade de realização do desejo de ser mãe, após a vivência de um período de infertilidade, tornou-se uma tarefa difícil e desafiadora para as participantes deste estudo. $O$ medo de perder o bebê e a ameaça de não conseguirem realizar o projeto parental dificultaram a aceitação de que o tratamento havia obtido sucesso e de que estavam grávidas.

Ao longo do relato das gestantes, foi possível verificar a presença dos temas da constelação da maternidade já durante o período gestacional, encontrando-se algumas semelhanças e particularidades que merecem destaque. Nesse contexto, foi possível observar que a reorganização psíquica dessas gestantes, uma espécie de movimento interno para abrigar o bebê, foi também entrelaçada pelo medo constante de perdê-lo, pelo sentimento de fragilidade e incapacidade de mantê-lo vivo, ainda intraútero. Observou-se, ainda, que esse medo foi expresso de forma peculiar pela participante receptora de gametas, ao visualizar os bebês de maneira fragmentada nas ecografias, ao referir-se a eles como fetos, embora estivesse no último trimestre gestacional. Portanto, acredita-se que o estigma da infertilidade e da dificuldade em realizar o projeto parental possa ter afetado a transição do status de infértil para fértil nessas mulheres, manifesto pela descrença na possibilidade de gerar um bebê saudável e garantir sua sobrevivência.

Com foco no relacionamento primário proposto pela constelação da maternidade, observou-se que Raquel e Vitória desejavam paralisar o entorno, a fim de que pudessem dedicar-se exclusivamente ao período gestacional; mas o mesmo não foi verificado no discurso de Simone. Quanto à matriz de apoio, percebe-se que as três participantes mostraram-se sensíveis à oferta de ajuda. O tema da reorganização da identidade foi manifestado com maior clareza por Simone, talvez pelo fato de os bebês não estarem geneticamente relacionados a ela, e por Vitória, pelo temor consciente de perder a identidade.

Quanto às semelhanças verificadas nos temas da constelação da maternidade, observou-se que o medo de perder o bebê e a descrença na capacidade de gerar um bebê saudável e garantir sua sobrevivência foram uma constante entre as três participantes, quando, nas gestações espontâneas, essa é uma característica que predomina no primeiro trimestre. Chama atenção, portanto, a persistência desse temor entre as gestantes, mesmo estando elas no último trimestre de gestação, quando o nascimento do bebê já é viável, e as expectativas em relação ao parto são predominantes. Pode-se inferir, dessa forma, que o sentimento de vulnerabilidade, semelhante nas três participantes deste estudo, representou temores já anunciados desde a gestação e pode constituir-se também uma particularidade da gestação no contexto das TRA. Esses achados corroboram a ideia de alguns autores (Balmaceda et al., 2001) de que as emoções presentes na gestação, após uma prolongada experiência de infertilidade, normalmente são mais intensas, o que torna o período gestacional uma transição entre a experiência da infertilidade e a experiência da maternidade em potencial. Segundo esses autores, um dos aspectos mais difíceis a serem enfrentados nessa transição é o medo de perder o bebê.

Foi possível perceber, também, que as "cicatrizes" deixadas pela infertilidade e seu tratamento permaneceram como pano de fundo da gestação, despertando nas gestantes sentimentos de fragilidade, incapacidade e descrença na possibilidade de possuir "coisas boas" dentro de si. Pode-se pensar também, que a gestação neste contexto talvez tenha sido vivida como um período de transição entre o status de infértil e a possibilidade de realizar o projeto parental. Ressalta-se que essa vivência constitui uma particularidade dessas gestantes que conceberam por TRA, não tendo sido referida por estudos com mulheres que conceberam naturalmente.

Dessa forma, entende-se que os sentimentos de fragilidade, incapacidade e medo, vivenciados pelas gestantes deste estudo, podem ter sido um obstáculo que dificultou, mas não impediu a gestação psíquica desse bebê: o bebê imaginário, que dará lugar ao bebê real no momento do nascimento. O fato de ser ele percebido em "partes", por exemplo, ou ser imaginado já crescido, aponta o medo das gestantes de se decepcionarem pela perda do bebê que vinha se desenvolvendo em seu útero.

Entretanto, ao significarem os movimentos do bebê, ou ao lhe atribuírem características dos signos astrológicos, essas mães estabeleceram uma ligação com o bebê, assegurando a ele um lugar na linhagem familiar. Por outro lado, a participante com doação de gametas apresentou dificuldade em fantasiar sobre 
como seriam os bebês, atendo-se apenas às informações concretas obtidas por meio do médico.

Considera-se que o processo de construção desse bebê imaginário assemelha-se à nidação do óvulo no útero, pois, assim como transformações biológicas fundamentais ocorrem ao longo da gestação, transformações psíquicas para receber esse bebê são igualmente necessárias. No que concerne ao bebê imaginário, pode-se perceber que, apesar do medo da perda do bebê, com todas as implicações mencionadas anteriormente, as participantes deste estudo puderam fantasiar em seu psiquismo o bebê que estava por chegar, assim como referido pela literatura em relacão à gestação espontânea. Apesar das evidências de que estavam grávidas, as participantes deste estudo demonstraram dificuldade em aceitar o novo status, vivendo esse momento em etapas, talvez pelo medo de perder o bebê.

Os resultados do presente estudo apontam que a gestação, no contexto das TRA, embora com alguns aspectos psicológicos semelhantes à gestação espontânea, apresenta desafios únicos, que conferem singularidade a esse momento. Entretanto, ainda são escassos os estudos sobre o tema, que contemplem a experiência subjetiva das gestantes e, assim, possibilitem aos profissionais compreender com maior profundidade esse contexto, promovendo a saúde da gestante e a relação com seu bebê.

Constatada a relevância desse contexto e suas prováveis implicações para a construção da maternidade, sugere-se que as mulheres que se submetem a tratamentos de reprodução assistida possam ter um espaço de escuta que privilegie o acolhimento, a compreensão e a instrução, para, assim, dar sentido ao que vivem e sentem.

\section{Referências}

Aulagnier, P. (1990). Um intérprete em busca de sentido. São Paulo: Escuta.

Balmaceda, R., Fernández, O., Fernández, E., Fabres, V., Huidobro, A., Sepúlveda, J., et al. (2001). Tener un hijo: conociendo la infertilidad y los caminos para resolverla. Santiago: Publicações Técnicas Mediterrâneo.

Barker, C., Pistrang, N., \& Elliot, R. (1994). Research methods in clinical counselling psychology. Chichester: John Wiley \& Sons.

Brazelton, T. B., \& Cramer, B. G. (1992). As primeiras relações. São Paulo: Martins Fontes.
Colpin, H., De Munter, A., \& Vandemeulebroecke, L. (1998). Parenthood motives in IVF-mothers. Journal of Psychosomatic Obstetrics and Gynecology, 19 (1), 19-27.

Ferriani, R., \& Navarro, P. (2004). Protocolos de conduta em infertilidade conjugal. São Paulo: Conexão Brasileira de Computação Gráfica.

Fisher, J. R. W., Hammarberg, K., \& Baker, G. H. W. (2008). Antenatal mood and fetal attachment after assisted conception. Fertility and Sterility, 89 (5), 1103-1112.

Hjelmstedt, A., Widström, A., Wramsby, H., \& Collins, A. (2003a). Patterns of emotional responses to pregnancy, experience of pregnancy and attitudes to parenthood among IVF couples: a longitudinal study. Journal of Psychosomatic Obstetrics \& Gynecology, 24 (3), 153-162.

Hjelmstedt, A., Widströn, A., Wramsby, H., Matthiesen, A., \& Collins, A. (2003b). Personality factors and emotional response to pregnancy among IVF couples in early pregnancy: a comparative study. Acta Obstetricia et Gynecologica Scandinavica, 82, 152-161.

Klock, S., \& Greenfeld, D. (2000). Psychological status of in vitro fertilization patient during pregnancy: a longitudinal study. Fertility Sterility, 73 (6), 1159-1164.

Laville, C., \& Dione, J. (1999). A construção do saber: manual de metodologia em ciências humanas. Porto Alegre: Artmed.

Lebovici, S. (1987). O bebê, a mãe e o psicanalista. Porto Alegre: Artes Médicas.

Lebovici, S. (1992). Maternidade. In G. Costa \& G. Katz (Eds.), Dinâmica das relações conjugais (pp.41-61). Porto Alegre: Artes Médicas.

Maldonado, M. T. (2002). Psicologia da gravidez, parto e puerpério. São Paulo: Saraiva.

McMahon, C., Gibson, F., Leslie, G., Cohen, J., \& Tennant, C. (2003). Parents of 5-year-old in vitro fertilization children: psychological adjustment, parenting stress, and the influence of subsequent in vitro fertilization treatment. Journal of Family Psychology, 17 (3), 361-369.

Núcleo de Infância e Família. (1998a). Entrevista de dados demográficos do casal. Manuscrito não-publicado, Instituto de Psicologia, Universidade Federal do Rio Grande do Sul, Porto Alegre.

Núcleo de Infância e Família. (1998b). Entrevista sobre a gestação e as expectativas da gestante. Manuscrito não-publicado, Instituto de Psicologia, Universidade Federal do Rio Grande do Sul, Porto Alegre.

Patton, M. Q. (2002). Qualitative research and evaluation methods ( ${ }^{\text {rd }}$ ed.). California: Sage Publications.

Piccinini, C. A., Gomes, A. G., Moreira, L. E., \& Lopes, R. C. S. (2004). Expectativas e sentimentos da gestante em relação ao seu bebê. Psicologia, Teoria e Pesquisa, 20 (3), 223-232.

Piccinini, C. A., Gomes, A. G., Nardi, T., \& Lopes, R. C. S. (2008). Gestação e a constituição da maternidade. Psicologia em Estudo (Maringá), 13, 63-72.

Raphael-Leff, J. (1997). Gravidez: a história interior. Porto Alegre: Artes Médicas. 
Repokari, L., Punamäki, P., Poikkeus, S., Vilska, S., UnkilaKallio, L., Sinkkonen, F., et al. (2005). The impact of successful assisted reproduction treatment on female and male mental health during transition to parenthood: a prospective controlled study. Human Reproduction, 20 (11), 3238-3247.

Ribeiro, M. (2004). Infertilidadee reprodução assistida: desejando filhos na família contemporânea. São Paulo: Casa do Psicólogo.

Sandelowski, M., Harris, B. G., \& Holditch-Davis, D. (1990). Pregnant moments: the process of conception in infertile couples. Research in Nursing \& Health, 13 (5), 273-282.

Stanton, F., \& Golombok, S. (1993). Maternal-fetal attachment during pregnancy following in vitro fertilization. Journal of Psychosomatic Obstetrics Gynaecology, 14 (2), 153-158.
Stern, D. N. (1997). A constelação da maternidade: o panorama da psicoterapia pais/bebê. Porto Alegre: Artes Médicas.

Szejer, M., \& Stewart, R. (1997). Nove meses na vida da mulher: uma abordagem psicanalítica da gravidez e do nascimento. São Paulo: Casa do Psicólogo.

Ulrich, D., Gagel, D. E., Hemmerling, A., PastorV.-S., \& Kentenich, H. (2004). Couples becoming parents: something special after IVF? Journal of Psychosomatic Obstetrics \& Gynecology, $25(2), 99-113$

Recebido em: 21/12/2009

Versão final reapresentada em: 17/5/2011

Aprovado em: 23/5/2011 
